\title{
LITERATURA COMPARADA: RAÍZES, RUMOS, PERSPECTIVAS
}

\author{
Entrevista com Eduardo de Faria Coutinho, \\ Ex-Presidente da Associação Brasileira de Literatura Comparada (ABRALIC) e atual \\ Vice-Presidente da Associação Internacional de Literatura Comparada (ICLA/AILC)
}

A presente entrevista foi realizada pelo doutorando Rafael Guimarães, do Programa de Pós-Graduação de Letras da UFRGS, e por Rita Terezinha Schmidt, Professora do Instituto de Letras, por via eletrônica, no período em que Eduardo de Faria Coutinho atuava como Professor-Visitante na Illionois University at Urbana-Champaign, EUA (2011-2012). Em sua estada na referida universidade, Eduardo de Faria Coutinho ministrou duas disciplinas no programa de pós-graduação (a primeira, Poetic Constructions and the Formation of the Cultural Imaginary in Brazil, e a segunda, The Search for Cultural Identity in Brazilian and Spanish-American Essay Writing), bem como proferiu várias palestras em outras instituições de ensino, dentre as quais, a Brown University e a Arizona University.

ORGANON: Muitos críticos brasileiros, como Antonio Candido e Augusto Meyer, e historiadores da literatura, como Otto Maria Carpeaux e Afrânio Coutinho (seu pai), compreenderam a importância da abordagem comparatista dos fenômenos literários. $\mathrm{O}$ senhor, por sua vez, desempenhou um papel importante na institucionalização do comparatismo na academia brasileira. $\mathrm{O}$ senhor poderia fazer um breve relato de como surgiu a ideia de criar a ABRALIC? De onde veio a vontade e/ou a necessidade de criar uma associação comparatista no país?

EDUARDO DE FARIA COUTINHO: Eu era professor de Literatura Brasileira na UFRJ nos anos de 1969 e 1970 e, embora me agradasse muitíssimo lecionar a nossa literatura, percebi àquela época que não era possível ministrar um curso satisfatório sem estar constantemente estabelecendo relações com outros sistemas literários. Não que a literatura brasileira não oferecesse um amplo manancial para estudo e discussão em sala de aula, mas estas discussões tornavam-se muito mais ricas e instigantes quando comparadas a outras obras, provenientes de outras literaturas nacionais. Como afirmou De Sanctis, com bastante propriedade, em seus Scritti, já em 1865-67, nenhuma literatura pode alimentar-se de si mesma ou escapar à influência de literaturas estrangeiras. Com isso em mente, achei que o caminho que mais satisfaria as minhas aspirações seria o da Literatura Comparada. Parti, então, com o estímulo de meu pai, Afrânio Coutinho, com quem compartilhei minhas preocupações, e que sempre fora um entusiasmado dos estudos comparados, para realizar o mestrado nos Estados Unidos, onde já havia uma tradição consolidada na área em questão. E escolhi a Universidade da Carolina do Norte, em Chappel Hill, em grande parte por ter sido esta a sede do II 
Congresso da Associação Internacional de Literatura Comparada (AILC/ICLA), de 1958, quando René Wellek, acompanhado de outros comparatistas radicados em universidades estadunidenses, iniciaram a famosa polêmica com os comparatistas franceses, dando origem às chamadas Escolas Francesa e Norte-Americana de Literatura Comparada. Concluído o mestrado, dei continuidade aos meus estudos comparatistas, realizando o doutorado na Universidade da Califórnia, em Berkeley, um dos maiores e mais reconhecidos polos de estudos sobre o assunto. De regresso ao Brasil, em 1977, comecei a lecionar a disciplina primeiramente em cursos de graduação na UFRJ, e em seguida, ingressei na Pós-Graduação, na área da Literatura Comparada do Programa de Ciência da Literatura. Desde os tempos de minha formação pósgraduada, nos Estados Unidos, especializei-me, dentro do âmbito da Literatura Comparada, nas literaturas de língua portuguesa, espanhola e inglesa do continente americano, em especial as duas primeiras, que nunca mais abandonei ao longo de toda a minha carreira.

Acompanhando com grande interesse, desde que regressei ao Brasil, a produção e as atividades que se vinham realizando na área dos estudos comparados, decidi participar, com a apresentação de um trabalho, e o auxílio precioso do CNPq, do XI Congresso da AILC/ICLA, realizado em Paris, em 1985. Foi lá então, em meio a intensos debates sobre todos os aspectos relacionados à disciplina, desde questões mais específicas pertinentes à narratologia, à semiologia e à estética da recepção, à época ainda muito em voga, até uma ampla discussão sobre a tradução, a oposição entre o oral e o escrito e os diálogos de culturas, que conheci Tania Franco Carvalhal, e demos início a uma parceria intelectual que não iria mais arrefecer. Professora de Literatura Francesa e Brasileira, com Doutorado na USP e ampla vivência do meio acadêmico francês, Tania também mergulhara no comparatismo e se encontrava àquela época grandemente seduzida pela possibilidade de desenvolvimento da área no Brasil. Dinâmica e empreendedora que era, sua proposta foi quase imediata: por que não fundamos uma associação nacional de Literatura Comparada como as que temos visto aqui representadas e a vinculamos à AILC/ICLA? Do susto inicial, passei à reflexão e brindamos a futura realização na recepção de encerramento do Congresso, junto a outras duas participantes brasileiras, em tarde memorável sobre as águas do Sena.

A ideia, felizmente, não ficou em projeto. O objetivo comum - o desejo de propiciar, através de um intercâmbio mais dinâmico com os demais polos de estudos da disciplina, um desenvolvimento verdadeiramente eficaz do comparatismo no Brasil - e a confluência de áreas de atuação distintas, mas complementares - Tania transitava sobretudo pelas literaturas francesa e brasileira, e eu pela brasileira e a hispanoamericana, além da norte-americana (que eu lecionara durante certo tempo) - foram responsáveis pelo resto da aproximação. De regresso ao Brasil, mantivemos contato e, após ampliarmos o grupo fundador com a inclusão de outros pesquisadores da matéria, de pontos distintos do país, fundamos, a 9 de setembro de 1986, na Universidade Federal do Rio Grande do Sul, em Porto Alegre, a Associação Brasileira de Literatura Comparada, a ABRALIC. E Tania, sua primeira presidente, organizou, dois anos depois, o primeiro congresso da Associação, também na UFRGS, onde estiveram presentes, além de um número expressivo de intelectuais brasileiros, quase todos os principais integrantes da então diretoria da AILC/ICLA.

As dificuldades na fase de implantação da ABRALIC foram evidentemente muitas, mas os esforços foram compensados. Hoje, a associação, que conta com mais de dois mil sócios, entre professores e pesquisadores de Literatura, é o principal órgão de 
estudos literários comparativos no Brasil, e o seu raio de atuação já alcançou amplas esferas, tendo constituído, inclusive, estímulo para a criação de novos cursos de pósgraduação na área. Suas atividades, nesses já vinte e cinco anos de existência, foram incontáveis, destacando-se, sobretudo, a realização de doze Congressos Internacionais de grande repercussão (Porto Alegre, Belo Horizonte, Niterói, São Paulo, Rio de Janeiro, Florianópolis, Salvador, Belo Horizonte, Porto Alegre, Rio de Janeiro, São Paulo e Curitiba), seguidos da publicação dos respectivos Anais, que constituem itens indispensáveis na bibliografia do comparatismo no Brasil. Além disso, há que se acrescentar a realização de diversos colóquios e seminários, e a criação de dois veículos sumamente importantes de divulgação: o Boletim Informativo Contraponto e a Revista Brasileira de Literatura Comparada, de qualidade reconhecida (extrato A1 na avaliação do WebQualis).

ORGANON: Recentemente, foi lançada a segunda edição da coletânea Literatura comparada: textos fundadores, organizada pelo senhor e pela professora Tania Franco Carvalhal. Não obstante a inegável importância histórica desses artigos, escritos por teóricos europeus e estadunidenses, que relevância, em sua opinião, as concepções basilares das chamadas escolas francesa e americana ainda apresentam para o contexto contemporâneo do comparatismo latino-americano?

EDUARDO DE FARIA COUTINHO: Nosso objetivo, ao organizar a primeira edição da antologia, foi dar a conhecer ao público brasileiro, em especial ao público universitário, alguns dos textos-chave que caracterizam os momentos mais importantes na evolução da disciplina. Daí a inclusão de uma seleção de textos das principais orientações que a disciplina seguiu ao longo de seu percurso histórico: as chamadas escolas francesa, norte-americana e soviética. Estes textos circuculavam pelo meio academico internacional em inglês, francês e outros idiomas, mas em sua maioria nunca tinham sido traduzidos para o português. São textos seminais, de grande valor histórico, mas cuja importância não se restringe a este aspecto. Neles se encontram também, entre outras coisas, valiosas reflexões sobre o fenômeno literário e as diversas maneiras de abordá-lo, além de discussões bastante instigantes sobre a teoria, a crítica e a historiografia literárias. É claro que a Literatura Comparada evoluiu muitíssimo de meados do século XX ao presente, tendo sofrido influência e absorvido contribuições de muitas das novas correntes de pensamento que se desenvolveram nesse período, dentre as quais a desconstrução, a nova história e os estudos culturais e pós-coloniais, mas a fim de conhecer as transformações por que passou a disciplina, e poder-se explorar suas relações com essas novas correntes, é preciso conhecer as bases que deram margem a essas transformações. Os primeiros estudos de Literatura Comparada na América Latina surgiram por influência do comparatismo francês (haja vista, entre outros, o livro de Tasso da Silveira intitulado Literatura comparada, um manual à maneira francesa), e posteriormente do norte-americano, e tais estudos não ficaram infensos à contribuição dos soviéticos; daí a necessidade de conhecer essas primeiras correntes, ainda que para pormos em xeque alguns de seus princípios básicos.

ORGANON: A Associação Brasileira de Literatura Comparada está comemorando 25 anos de existência. Olhando retrospectivamente para essas duas décadas e meia, que marcos o senhor apontaria como os mais significativos para a consolidação não só da 
ABRALIC, mas também da Literatura Comparada como disciplina e campo de investigação no Brasil?

EDUARDO DE FARIA COUTINHO: Eu não diria que houve marcos específicos. Houve, sim, acontecimentos importantes que derivaram em grande parte da criação da ABRALIC. O primeiro deles foi a realização dos doze congressos internacionais, seguidos da publicação dos Anais, que fornecem um retrato bastante bem delineado do comparatismo no Brasil. Em seguida, viria a publicação da Revista Brasileira de Literatura Comparada, um dos principais veículos de divulgação da produção na área, e o surgimento de livros sobre o assunto, antes muito escassos. Mas talvez o mais significativo de todos esses acontecimentos tenha sido a criação de novos cursos de PósGraduação na área em diversas universidades em todo o país e a adoção, em algumas delas, da disciplina em nível de graduação. Some-se a tudo isso a participação crescente de pesquisadores brasileiros nos Congressos da AILC/ICLA e na diretoria da Associação. Tania Franco Carvalhal foi membro do Conselho da Associação durante duas gestões consecutivas, em seguida Vice-Presidente, e posteriormente a primeira Presidente latino-americana da AILC, e eu, depois de membro do Conselho por também duas gestões consecutivas, sou atualmente Vice-Presidente, já também na segunda gestão. Além disso, fomos ambos coordenadores do Comitê de Pesquisa sobre a América Latina, cada um também por duas gestões. O comitê visou, entre outras coisas, a disseminação da Literatura Comparada em outros países da América Latina, com a realização de eventos e publicações, e estimulou a criação e a consolidação de outras associações nacionais no continente.

ORGANON: Em texto publicado no segundo número da Revista Brasileira de Literatura Comparada, em 1994, a professora Tania Franco Carvalhal indicava algumas perspectivas para os estudos comparados no século que se anunciava, dentre as quais estavam a verificação de uma maior proximidade entre a Literatura Comparada e os Estudos de Tradução, o surgimento de novas comunidades interliterárias a partir do desmembramento das antigas comunidades politicamente definidas, o esgotamento da reflexão teórica excessivamente abstrata, com um interesse maior na aplicabilidade da teoria em leituras críticas, além de uma consolidação da disciplina, especialmente em países onde os estudos comparados eram esporádicos. Hoje, passada já mais de uma década do século XXI, é possível dizer que o cenário "previsto” por Carvalhal tornou-se realidade? Além das questões apontadas por Carvalhal, a Literatura Comparada dá sinais de seguir outros caminhos neste início de milênio?

EDUARDO DE FARIA COUTINHO: Como afirmei acima, a Literatura Comparada passou por relevantes transformações de meados do século XX ao presente, encontrando-se, a meu ver, em uma fase de grande vitalidade. E as transformações por que a disciplina passou foram muito similares às que passaram os estudos literários de maneira geral. As correntes crítico-teóricas que se desenvolveram ao longo das últimas décadas atuaram sobre a Literatura Comparada de modo bastante profícuo, ampliando em muito sua esfera de atuação, antes bastante restrita ao viés considerado erudito da tradição literária e às literaturas consagradas pelo cânone ocidental. Com o questionamento dos pilares que sustentavam o comparatismo tradicional, como os conceitos de "nação", "idioma" e "literariedade", a Literatura Comparada passou a abarcar um espectro muitíssimo mais rico de textos não apenas provenientes de locais 
e/ou em idiomas até então não levados em conta, como também de outras searas do conhecimento, que não a estritamente literária. Nesse sentido, parece-me que as previsões de Tania Franco Carvalhal em 1994 vieram a concretizar-se, sobretudo no que diz respeito à aproximação aos estudos de tradução, ao surgimento de novas comunidades interliterárias e à consolidação da disciplina principalmente nos países onde os estudos comparados eram ainda esporádicos. Com relação à teoria, cabe lembrar, entretanto, que teoria literária e literatura comparada não se opõem em momento algum; antes complementam-se, e que, sendo a teoria um discurso sobre a literatura, uma reflexão sobre a produção literária, o que se tem verificado é não sua aplicabilidade, mas o diálogo que se estabelece entre o corpus literário e as reflexões já desenvolvidas ou a serem desenvolvidas sobre ele.

ORGANON: Se por um lado o Brasil esteve, em larga medida, historicamente de costas para a América Latina, a literatura comparada parece ter sido, desde sua consolidação como disciplina no país, ponto de convergência e palco de um diálogo intenso entre pensadores brasileiros e hispano-americanos. Podem ser apontados como exemplo dessa inter-relação a conhecida amizade e troca intelectual entre Angel Rama e Antonio Candido, alám da frequente presença nos congressos da ABRALIC de nomes como os das argentinas Adriana Crolla, Beatriz Sarlo e Zulma Palermo, da chilena Ana Pizarro e do uruguaio Pablo Rocca, só para citar alguns. Como o senhor avalia esse diálogo acadêmico além-fronteiras?

EDUARDO DE FARIA COUTINHO: O diálogo entre intelectuais brasileiros e os nossos vizinhos do continente é algo sem dúvida fundamental, e para o qual a literatura comparada vem contribuindo desde antes de sua consolidação no meio acadêmico de nosso país. Na época em que eu fiz meus estudos de pós-graduação nos Estados Unidos, tomei contato com a obra de muitos estudiosos que já demonstravam essa preocupação, principalmente no plano da ensaística, como Alfonso Reyes, Pedro Henríquez Ureña, Angel Rama, e os nossos Darcy Ribeiro e Antonio Candido, e fiz minha dissertação de mestrado e tese de doutorado em literatura comparada sobre autores brasileiros e hispano-americanos. Mais tarde, quando lecionei a disciplina na UFRJ, dei continuidade a esse diálogo, utilizando sempre como corpus literário de meus cursos autores provenientes dos dois universos. Recentemente, porém, com o desenvolvimento do comparatismo no Brasil, este diálogo acirrou-se consideravelmente, em especial após a criação da ABRALIC, que passou a convidar para os seus congressos e colóquios figuras de destaque do meio intelectual hispano-americano, como é o caso dos acima mencionados. Finalmente, com a criação tambám de associações de Literatura Comparada em países da América Hispânica - fato que se deve em grande parte ao empenho de Tania Franco Carvalhal -, como ocorreu com a Argentina, o Uruguai e o Peru, este diálogo atingiu um estágio bastante frutífero de verdadeiro intecâmbio, e tem desempenhado um papel de relevo nas relações interamericanas, dentro e fora da área dos estudos literários, ou até mesmo das humanidades, de modo geral.

ORGANON: Embora a Literatura Comparada tenha, em especial nas últimas décadas, revisado e redimensionado de forma profunda suas questões teóricas, epistemológicas e metodológicas centrais, a interdisciplinaridade permanence sendo um dos principais alicerces das análises comparatistas. Atualmente, com que áreas das artes e do 
conhecimento o senhor observa um maior interesse de aproximação com a literatura por parte dos estudos comparados?

EDUARDO DE FARIA COUTINHO: A interdisciplinaridade sempre foi, desde a configuração e a consolidação da Literatura Comparada como disciplina acadêmica, uma de suas marcas fundamentais, haja vista os estudos das relações entre a literatura e as demais formas de manifestação artística, como a música, as artes plásticas e o cinema, e das relações entre a literatura e outras formas de conhecimento, como a psicologia, e em particular a psicanálise, a sociologia, a antropologia, a filosofia e a história, para citar apenas algumas das mais frequentes. No entanto, com o desenvolvimento da disciplina e a inter-relação crescente que se vem observando entre as áreas do conhecimento, esta interdisciplinaridade vem se tornando cada vez maior, chegando a ser hoje uma espécie de palavra de ordem no âmbito dos estudos comparados. E o que é mais interessante é que ela vem ampliando de tal modo o seu escopo, que tem abarcado inclusive áreas até recentemente pouco permeáveis à imbricação de saberes, como a das ciências mais exatas.

ORGANON: Como atual Vice-Presidente da Associação Internacional de Literatura Comparada, como o senhor avalia a atuação da Associação, em termos de seus comitês e das suas respectivas abrangências, bem como das temáticas propostas dos congressos mais recentes? No seu ponto de vista, há uma justificativa para se voltar a discutir objetos e métodos do comparatismo, temática do Congresso da AILC/ICLA a se realizar em Paris, no ano de 2013?

EDUARDO DE FARIA COUTINHO: A Associação Internacional de Literatura Comparada tem tradicionalmente dois tipos de comitês, voltados para $\mathrm{o}$ desenvolvimento da pesquisa, o estabelecimento de fóruns de debate internacionais e a elaboração de publicações. O primeiro tipo é um comitê de longa duração, centrado em pesquisas que requerem um tempo mais extenso de elaboração e a publicação de trabalhos de maior fôlego, e o segundo um tipo de comitê mais voltado para assuntos do momento ou para questões que apresentam resultados em um lapso temporal mais curto. Estes últimos geralmente têm a duração de dois anos, podendo o seu tempo ser estendido a outro periodo similar. Em casos excepcionais, estes comitês transformam-se em comitês de longa duração, passando a ter então os encargos e características dos primeiros. Como em toda associação de grande abrangência, os comitês da AILC/ICLA dependem em geral do grupo que os compõe e da liderança que apresentam, podendo ser mais ou menos produtivos em decorrência de tais fatores. Assim, há comitês que apresentaram modestos resultados sob a forma de publicação e outros que já produziram obras de grande envergadura, como o designado Coordinating Committee, que tem publicado um número respeitável de histórias literárias, consideradas no plano internacional o que há de mais inovador na área, como é o caso da Literary Cultures of Latin America: a Contemporary History, organizada por Mario Valdés, Linda Hutcheon e Djelal Kadir, e publicada em 2004 pela Oxford University Press, ou dos volumes International Postmodernism, organizado por Hans Bertens e Douwe Fokkema, e publicado em 1996, e Modernism, organizado por Astradur Eysteinsson e Vivian Liska e publicado em 2007, ambos pela John Benjamins, de Amsterdam. No caso dos comitês de curta duração, a situação é semelhante, havendo os que apresentaram produção escassa e os que, como o de Estudos Latino-Americanos, iniciado por Tania Franco 
Carvalhal, se caracterizaram por expressivas publicações. Quanto ao temário dos congressos, ele tem variado significativamente e em geral está voltado para questões que vem inquietando os estudiosos. A proposta é feita em reunião do Comitê Executivo e aprovada ou não de acordo com a posição dos membros integrantes. A proposta do próximo congresso foi aprovada com base na ideia de que nunca é demasiado indagarse sobre os objetos e métodos do comparatismo, particularmente no momento em que a disciplina vem apresentando tão significativas transformações.

ORGANON: Para finalizar, o que o senhor considera mais importante no legado deixado por Tania Franco Carvalhal?

EDUARDO DE FARIA COUTINHO: Foram tantas as contribuições deixadas por Tania Franco Carvalhal, sobretudo para o desenvolvimento do comparatismo no Brasil, que seria difícil destacar uma ou hierarquizá-las em termos de sua relevância. No entanto, vale mencionar os livros que escreveu, dentre os quais A evidência mascarada: uma leitura da poesia de Augusto Meyer (1983) e O próprio e o alheio: ensaios de literatura comparada (2003), e os que organizou, em especial sobre os autores de sua terra (Rio Grande do Sul), sua atuação como pensadora, que soube muito bem dosar a prática acadêmica e a vivência no meio intelectual e artístico dentro e fora de seu país, seu caráter empreendedor, que soube tornar concretas e manter com pulso firme muitas de suas idealizações e, no âmbito mais específico da Literatura Comparada, a criação da ABRALIC e sua participação, primeiro como membro do Comitê Executivo, e finalmente como Presidente, da Associação Internacional de Literatura Comparada. Graças à sua atuação em todas as esferas mencionadas, mas em particular na última, seu nome acha-se hoje vinculado ao impulso que tomou a disciplina no Brasil. 